during the LIA. Again, these changes can be attributed to shifts of the SHWs. Additionally, lacustrine investigations (Haberzettl, 2006; Stine and Stine, 1990) indicate lower temperatures and wetter conditions in Patagonia during the LIA. Pollen-based results point to vegetation-type changes from dry to wet species. The latter can also be attributed to shifts in the SHWs (Mayr et al., 2007). Further, the analysis of glaciers and moraines in Patagonia show extensive glaciation during the LIA (Harrison et al., 2006, Koch and Kilian, 2005, Thompson et al., 1986).
Therefore, the comparison between proxy-based reconstructions and results from the GCM simulation show that both, model and proxy data indicate a climatically anomalous period between the mid16th and 19th century over southern South America. This suppors the hypothesis that the LIA, as indicated in proxy based and modeled northern hemispheric temperatures, is also reflected in hydrological variables over parts of the southern hemisphere.

\section{References}

Harrison, S., Glasser, N., Winchester, V., Haresign, E., Warren, C. and Jansson, K., 2006: A glacial lake outburst flood associated with recent mountain glacier retreat, Patagonian Andes, The Holocene, 16(4): 611-620.

Lara, A. and Villalba, R., 1993: A 3620-Year Temperature Record From Fitzroya cupressoides Tree Ring in Southern South America, Science, 260: 104-1106.

Mayr, C. et al., 2007: Holocene variability of the Southern Hemisphere westerlies in Argentiniean Patagonia $\left(52^{\circ} \mathrm{S}\right)$, Quaternary Science Reviews, 26: 579-584.

von Storch, H., Zorita, E., Jones, J., Dimitriev, Y., González-Rouco, F. and Tett, S., 2004: Reconstructing past climate from noisy data, Science, 306: 679-682.

Wagner, S., Widmann, M., Jones, J., Haberzettl, T., Lücke, A., Mayr, C., Ohlendorf, C., Schäbitz, F. and Zolitschka, B., 2007: Transient simulations, empirical reconstructions and forcing mechanisms for the Mid-Holocene hydrological climate in Southern Patagonia, Climate Dynamics, 29: 333-355.

\title{
Three-dimensional radiocarbon modeling: A tool to assess the last glacial ocean circulation and radiocarbon chronologies
}

\author{
Martin Butzin ${ }^{1,2}$, M. Prange ${ }^{1}$ and G. Lohmann ${ }^{2}$ \\ ${ }^{1}$ Center for Marine Environmental Sciences, University of Bremen, Germany; mbutzin@marum.de \\ ${ }^{2}$ Alfred Wegener Institute for Polar and Marine Research, Bremerhaven, Germany
}

At the Last Glacial Maximum (LGM), the overturning circulation of the ocean was probably quite different from today. The changes are still debated, as the current generation of coupled climate models arrive at contradictory results (e.g., OttoBliesner et al., 2007), and paleoceanographers face the problem of extracting robust and unambiguous information from proxy data.

In an attempt to reconcile observations with modeling, we simulated the distribution of marine radiocarbon $\left({ }^{14} \mathrm{C}\right)$ at the LGM, using a three-dimensional ocean general circulation model connected with an atmospheric radiocarbon reservoir (Butzin et al., 2005). The ocean model has an effective horizontal resolution of $3.5^{\circ}$, with a vertical resolution of 22 depth levels, and it is forced with atmospheric fields, which were derived in previous glacial climate simulations (as described by Prange et al., 2004). In a series of sensitivity studies with constant boundary conditions, we explored the influence of sea surface temperatures, sea ice extent, wind stress, and Antarctic sea ice formation on the glacial ${ }^{14} \mathrm{C}$ distribution and on the meridional overturning circulation (MOC).

Our simulations reveal a crucial influence of the background climate conditions on the results. The best agreement of modeled ${ }^{14} \mathrm{C}$ distributions with glacial ${ }^{14} \mathrm{C}$ observations is for a model run with significant MOC changes in the Atlantic, where the North Atlantic Deep Water (NADW)

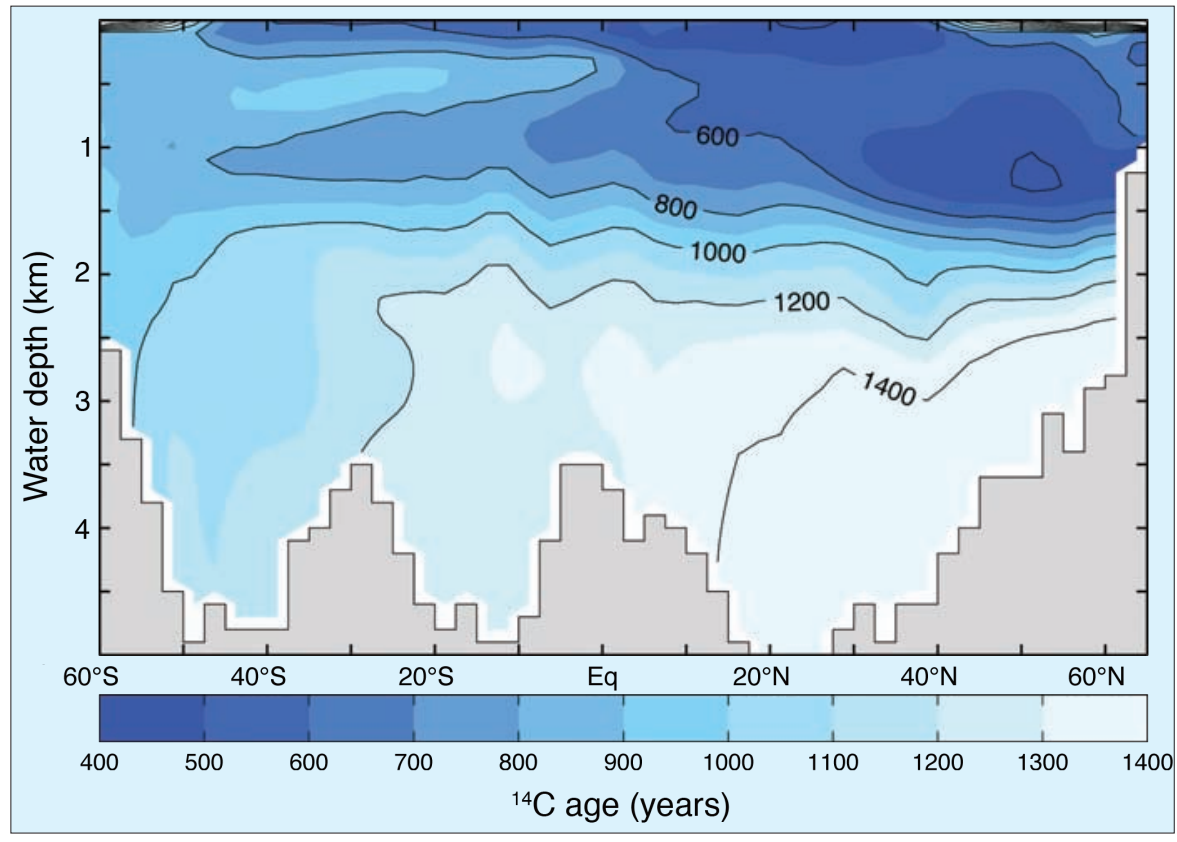

Figure 1: Radiocarbon age in the western Atlantic (along the GEOSECS track) according to simulations for the Last Glacial Maximum (Butzin et al., 2005).

shallows to a depth above about $2 \mathrm{~km}$ and weakens by about $40 \%$ compared to the present day. Conversely, Antarctic Bottom Water flow intensifies and compensates for the weakened NADW transport into the South Atlantic. As a consequence, the modeled abyssal glacial Atlantic is depleted in ${ }^{14} \mathrm{C}$ (Fig. 1), very cold and very saline. These results are in line with proxy data evidence (see Lynch-Stieglitz et al., 2007, for a review).

Radiocarbon concentrations in environmental samples are frequently quoted in the form of ages relative to atmospheric
${ }^{14} \mathrm{C}$ values. Applying the law of radioactive decay, high ${ }^{14} \mathrm{C}$ concentrations translate into low ${ }^{14} \mathrm{C}$ ages, and vice versa. Radiocarbon concentrations of the present-day surface ocean correspond to an apparent marine reservoir ${ }^{14} \mathrm{C}$ age (MRA) of about $400 \mathrm{yr}$ in the global mean, and range from about $300 \mathrm{yr}$ in the subtropics to $1000 \mathrm{yr}$ at high latitudes (e.g., Key et al., 2004). Our simulations indicate generally higher MRAs for the LGM (Fig. 2). This reflects slower uptake of ${ }^{14} \mathrm{C}$ by the glacial ocean, which is predominantly due to the reduced partial pressure of atmospheric $\mathrm{CO}_{2}$ 


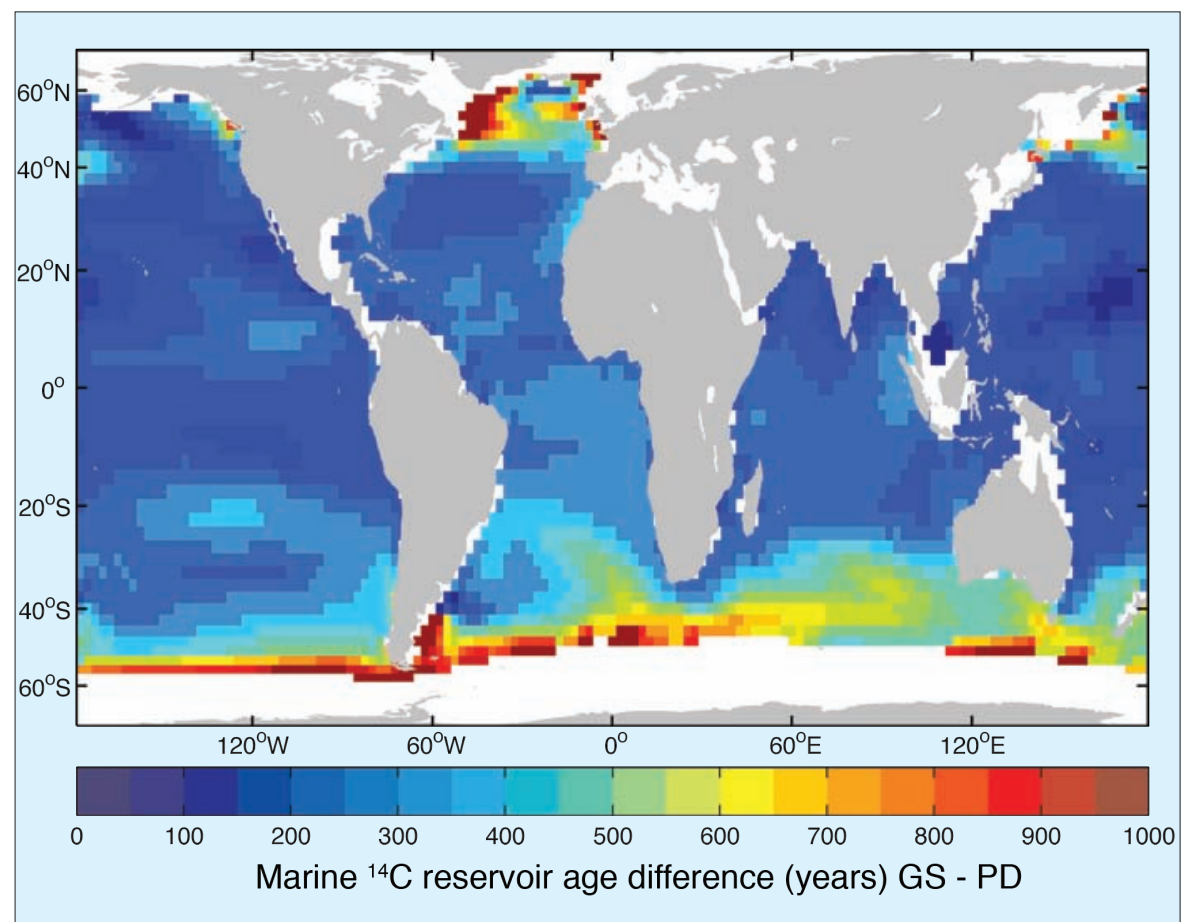

Figure 2: Marine reservoir age difference between the glacial (GS) and the present-day (PD) ocean, based on model calculations (Butzin et al., 2005).

and weakened MOC at the LGM. The spatial and temporal variability of MRAs is a critical factor in ${ }^{14} \mathrm{C}$ dating. Beyond the tree ring record (i.e., before ca. $12.4 \mathrm{cal} \mathrm{kyr} \mathrm{BP),}$ atmospheric chronologies for ${ }^{14} \mathrm{C}$ dating rely to a large extent on cross-dated marine archives such as laminated sediments or corals. Although there is observational evidence for considerable MRA changes during the last deglaciation (e.g., see Cao et al., 2007, and references therein), most ${ }^{14} \mathrm{C}$ chronologies have not included this effect but assume time-invariant MRA values.

For this reason, we devised a self-consistent iteration scheme in which existing radiocarbon chronologies for the last deglaciation can be readjusted by transient, three-dimensional simulations of marine and atmospheric $\Delta^{14} \mathrm{C}$ (Butzin et al., 2008). The idea is to infer atmospheric $\Delta^{14} \mathrm{C}$ from marine reconstructions by back and forth model calculations. The iteration scheme starts with a prescribed atmospheric $\Delta^{14} \mathrm{C}$ chronology (derived from marine data assuming a certain inverse MRA correction), and uses an ocean model to diagnose the corresponding evolution of marine $\Delta^{14} \mathrm{C}$. If there are differences between model results and reconstructions, the atmospheric chronology has to be adjusted by applying a modified MRA correction, and the ocean model is rerun using this new atmospheric ${ }^{14} \mathrm{C}$ input curve. The procedure is repeated until model results and reconstructions converge, which implies that atmospheric $\triangle{ }^{14} \mathrm{C}$ values and MRAs are consistent with marine reconstructions.

To estimate the uncertainties associated with the intensity of ocean ventilation lennia of the simulations may be biased by the model's adaptation to the transient ${ }^{14} \mathrm{C}$ input history. The readjustment points to MRAs of $100-850 \mathrm{yr}$ in the Cariaco Basin during the last deglaciation. Correspondingly, the variability of re-adjusted atmospheric $\Delta^{14} \mathrm{C}$ increases by -50 to $+100 \%$, and increases the mysterious drop of atmospheric concentrations between 17.5 and 14.5 cal kyr BP discussed by Broecker and Barker (2007).

Our readjustment approach is complementary to statistical methods devised for the estimation of ${ }^{14} \mathrm{C}$ chronologies (such as devised by Buck and Blackwell, 2004). Uncertainties of this approach due to potential model deficiencies could be narrowed down by ensemble and intercomparison runs.

\section{References}

Butzin, M., Prange, M. and Lohmann, G., 2005: Radiocarbon simulations for the glacial ocean: The effects of wind stress, Southern Ocean sea ice and Heinrich events, Earth and Planetary Science Letters, 235: 45-61.

Cao, L., Fairbanks, R.G., Mortlock, R.A. and Risk, M.J., 2007: Radiocarbon reservoir age of high latitude North Atlantic surface water during the last deglacial, Quaternary Science Reviews, 26: 732-742.

Hughen, K.A., Southon, J., Lehman, S., Bertrand, C. and Turnbull, J, 2006 Marine-derived ${ }^{14} \mathrm{C}$ calibration and activity record for the pas 50,000 years updated from the Cariaco Basin, Quaternary Science Reviews, 25: 3216-3227.

Lynch-Stieglitz, J., et al., 2007: Atlantic Meridional Overturning Circulation During the Last Glacial Maximum; Science, 316: 66-69.

Otto-Bliesner, B.L., Hewitt, C.D., Marchitto, T.M., Brady, E., Abe-Ouchi, A., Crucifix, M. Murakami, S. and Weber, S.L., 2007: Last Glacial Maximum ocean thermohaline circulation: PMIP2 model intercomparison and data constraints, Geophysical Research Letters, 34: L12706.

originally assumed a time-invariant MRA value of $420 \mathrm{yr}$ (Hughen et al. 2006; see Fig. 3). Our simulations started from steadystate conditions at 25 cal kyr BP assuming atmospheric $\Delta^{14} \mathrm{C}=530 \%$. We focused on the period 20-14 cal kyr BP, as the first mil-

For full references please consult:

www.pages-igbp.org/products/newsletter/ref2008_2.html

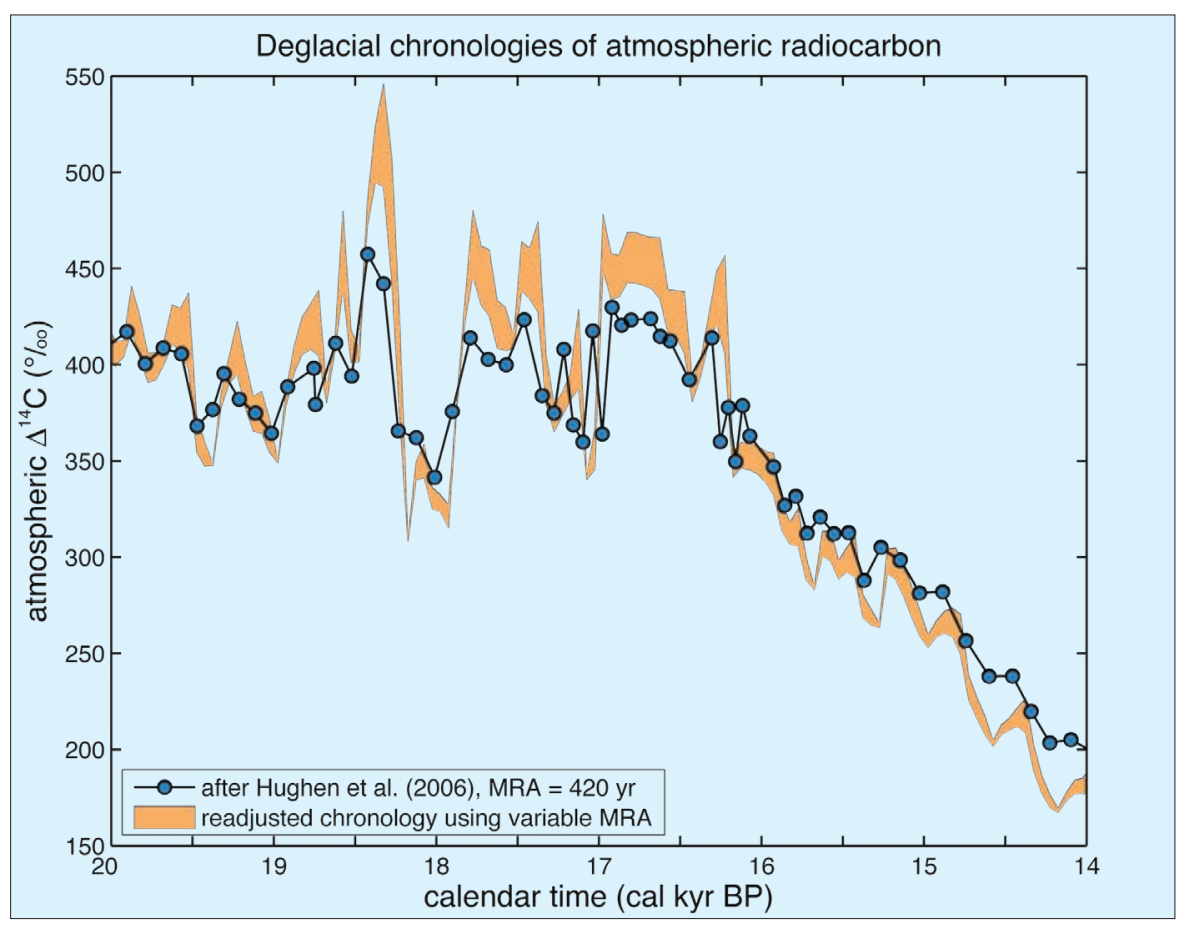

Figure 3: Readjustment of an atmospheric ${ }^{14} \mathrm{C}$ chronology (Hughen et al., 2006, originally assuming a time-invariant marine reservoir age correction of $420 \mathrm{yr}$ ) by self-consistent modeling. Different climatic forcing scenarios yield upper and lower bounds spanning the uncertainty range of the readjustment approach (Butzin et al., 2008). 